\title{
The Role of Religious Leaders On The Use of HIV/AIDS Prevention Strategies Among Young People (15-24) in Lira District, Uganda
}

\section{Tom Murungi}

Lira University

Irene Kunihira

Lira University

Pamela Oyella

Lira University

Moses Mugerwa

Lira University

\section{Peruth Gift}

Lira University

Mercy Jane Aceng

Lira University

Lydia Abolo

Lira University

Sean Steven Puleh ( $\nabla$ spuleh@lirauni.ac.ug )

Lira University

\section{Research Article}

Keywords: Role, Religious leaders, HIV prevention strategies, Young people, Use

Posted Date: July 7th, 2021

DOI: https://doi.org/10.21203/rs.3.rs-664256/v1

License: (1) (1) This work is licensed under a Creative Commons Attribution 4.0 International License. Read Full License 


\section{Abstract}

Background: Young people (15-24 years) bear the highest burden of new infections and are particularly vulnerable because of their highly risky behavior. There is paucity of information on the role of religious leaders in the multi-sectoral fight against HIV/AIDS. We examined the role of religious leaders in the use of HIV prevention strategies among young people.

Methods: A cross sectional study was conducted between March and April 2021 among 422 randomly selected young people in Lira district. An interviewer administered a questionnaire to the young people in order to collect quantitative data. About 20 key informants were purposively sampled and interviews were conducted with religious leaders using a key informant's interview guide. Data was collected on social demographics, HIV prevention messages, and awareness about HIV prevention strategies. Data was analyzed using Stata version 15 using proportions, means, percentages, frequencies, and logistic regression analysis at a $95 \%$ level of significance. Qualitative data was analyzed using thematic content analysis and the major themes were generated from the participants' responses.

Results. About $57.1 \%$ (241/422) of the respondents were females. The prevalence of use of HIV prevention strategies among young people was $69.4 \%$. Factors significantly associated with the use of HIV prevention included completing the primary level (aOR 4.95, $p<0.05)$, completing at least A level (aOR 8.85, $p<<0.05$ ), Awareness of HIV prevention strategies by religious leaders (aOR $0.02, p<0.001$ ), religious leaders provided HIV prevention messages (aOR 2.53, $p<0.01$ ), Advocacy for abstinence outside marriage and fidelity in marriage (aOR 35.6, $\mathrm{p}<0.01)$, Religious leaders preaching about HIV prevention (aOR 4.88, $p<0.001)$.

Our qualitative data indicated that a section of religious leaders recommended abstinence/faithfulness. Condom use was the most discouraged HIV prevention strategy. However, most religious leaders agree with the fact that they have a role to play in HIV prevention, which includes sensitization, teaching and organizing sermons about HIV prevention.

Conclusion: The use of HIV prevention strategies by religious leaders among young people was nearly $70 \%$. This finding indicates that religious leaders have a role to play in HIV/AIDS prevention among young people in the Lira district. This calls for the involvement of religious leaders in HIV prevention programs tailored to prevent new infections of HIV among young people.

\section{Introduction}

Globally, 38 million people live with HIV, 1.5 million people become infected yearly and about 34.7 million people have died from AIDS related illnesses since the start of the epidemic [1]. An estimated 40 percent of the new HIV infections worldwide occur among young people aged 15-24 years [2]. In addition, over $30 \%$ of all daily new infections are projected to occur among young people aged 15-24 years, with males and females disproportionately affected at $12 \%$ and $30 \%$ respectively [3]. Data from UNICEF shows that 460,000 young people (10-24) were newly infected with HIV [4]. Sub-Saharan Africa (SSA) bears the 
greatest burden of HIV/AIDS, accounting for the greatest number of new infections and deaths worldwide [5]. Young people account for approximately $20.6 \%$ of Uganda's population [6] with 170000 of them infected with HIV [7].

Young people (15-24 years) are particularly important because they bear the highest burden of HIV new infections [1]. In addition, young people are regarded as vulnerable because they tend to have the most risky behavior, amidst several challenges, including physiological changes, peer pressure, among others [8]. In addition, other studies have also reported early sexual debuts among students, which is a risk factor for sexually transmitted infections and HIV acquisition [9]. Uptake of HIV prevention services among young people is low and there is no gold standard intervention in regards to HIV prevention among young people in SSA [10, 11]. HIV prevention strategies for young people necessitate multifaceted interventions [12]. Previous research has suggested linkages between the involvements of Faith-Based Organizations (FBO) in campaigns to prevent HIV/AIDS, but the role of religious leaders seems unclear. For example, there is no evidence of studies that have evaluated to what extent religious leaders have played a role in HIV/AIDS prevention programmes among young people as fundamental actors. Religious leaders in this study are individuals recognized as having authority within a specific religion, such as Pastors, Reverends, Bishops, Catechists, Priests, Sheikhs, and Imams. Uganda is a multi-denominational country, with approximately $82 \%$ of the population being Christians, $14 \%$ being Muslims, and less than $5 \%$ belonging to other religions, according to the 2014 national census [13]. Given the status religious leaders hold in many societies, they frequently have contact with communities and can utilize their pulpits to reach out to many, especially young people in hard-to-reach areas [14]. In addition, religious leaders can use their positions to break the silence surrounding HIV/AIDS, shape social values, disseminate accurate information and influence opinion [15]. However, the levels and intensity of engagement by religious leaders and how they are likely to influence the use of HIV prevention strategies among young people has not been studied.

HIV prevention strategies refer to ways in which individuals can reduce the risk of HIV infection by limiting exposure to risk factors. Condom use, safe male circumcision, pre exposure prophylaxis (PEP), elimination of mother-to-child transmission (EMTCT), testing and counseling for HIV and sexually transmitted infections (STI) have been adopted as some of the HIV prevention strategies. However, there is a paucity of information regarding the role of religious leaders on the use of HIV prevention strategies among young people. Evidence from a similar setting focused on religious leaders' involvement in HIV prevention and care for gays, bisexual men, and others who have sex with men [16]. Some studies have only looked at involving religious leaders in HIV care and treatment at health facilities [17]. Because of the importance of religious beliefs in the prevention of HIV/AIDS, it is critical to assess religious leaders' roles in the use of HIV prevention strategies among young people in Lira district. This study has generated evidence based data for programming and policy development to improve the involvement of religious leaders in the use of HIV prevention strategies among young people.

\section{Methods}




\section{Study design}

A cross-sectional survey using quantitative and qualitative methods was carried out in March and April, 2021.

\section{Study setting}

The study was conducted in the greater Lira district, which is divided into Lira City and Lira District Local Government, in Northern Uganda. Lira City is further divided into two (02) divisions Lira City East and Lira City West, and Lira District Local Government divided into Erute North and Erute South. Lira district is bordered by Pader district to the North, Otuke to the East, Dokolo to the South West and Kole to the West. It has an estimated population of about 478,500 . It is about $380 \mathrm{~km}$ from Kampala, the capital of Uganda.

\section{Study population}

The study was conducted among 422 young people aged between 15 to 24 years living in Lira district, Northern Uganda, to collect quantitative data. The term young people was used to represent a period of changeover from childhood and dependence to adulthood and independence, a stage thought to have several behavioral, social challenges and vulnerability [18]. We also conducted 20 key informant interviews with religious leaders who are recognized as having authority within their respective religions, such as pastors, reverends, deacons, bishops, catechists, priests, sheikhs, and imams.

\section{Sample size estimation}

The Cochran's formula (1997) was used to calculate the sample size for young people.

Based on the assumptions that $p=0.5$ and $d=0.05, q=1-p$, and $d=$ margin of error, our sample size is $=$ 384 if we assume a probability of $50 \%$. With a $10 \%$ non-response rate, our sample size was $n=422$. Key informant interviews were conducted with 20 religious leaders who were sampled purposively.

\section{Data collection procedure}

This was a mixed method study using both quantitative and qualitative methods. We collected qualitative data first, followed by quantitative data. Quantitative data was collected using interviewer administered questionnaires and an interview guide was used to gather information from the religious leaders of the different denominations under the study. We developed our study tools and adapted some interview questions from other studies done in a similar setting $[19,20]$. Our study tools were pretested on 20 young people and adjusted accordingly.

Written consent was sought from all participants before screening to determine their eligibility to participate in the survey. Assent and consent was sought from all respondents who were 15 to 17 and those at least 18 years respectively before their participation. Participants were interviewed in turn until the quota was reached per village. These interviews took about 15-20 minutes on average. Consenting religious leaders were interviewed using an interview guide to collect qualitative data and the interviews 
lasted between 20 and 25 minutes. All research assistants were trained prior to data collection. All study tools were reviewed for completion at the end of data collection to ensure the quality of the data.

\section{Sampling criteria.}

The religious leaders and young people were chosen using a multi-stage cluster sampling technique. The study site was classified as rural (Lira district) and urban (Lira City). One county/division was selected from each cluster using simple random sampling. Three sub-counties were sampled from each county using a table of random numbers. Three (3) parishes/wards were sampled from each sub county using a table of random numbers. A simple random sampling technique was used to select one village/ cell from each parish/ward. Convenience sampling was used to select religious leaders to include all dominant religious denominations. Those who met the inclusion criteria and consented were included. Those who were eligible were recruited from the villages/cells until the sample size was reached.

\section{Data management}

In the field, questionnaires were checked for completeness. For participants who were unable to read or write, a witness was involved to ensure transparency. Data was entered into SPSS version 23 with consistency checks to ensure correctness. The dataset was cleaned for out of range values and exported to STATA 15 (StataCorp, College Station, TX) software.

For the key informant interviews, all the interview recordings were checked at the end of every interview to ensure completeness. All questions were asked in order and, where necessary, probing was done to make the questions clearer for the respondent. Audios were kept on hard drives, only accessible to the study team. Unique identification numbers were used to identify participants to ensure confidentiality.

\section{Data analysis plan}

We summarized and conducted a descriptive analysis to determine the proportions of the different variables in the respondents' characteristics. In this study, categorical variables such as place of residence and sex refer to biological differences between females and males, such as chromosomes, sex organs, and endogenous hormonal profiles. Marital status and level of education were analyzed and expressed as frequencies and proportions, whereas continuous variables such as age were expressed as means (standard deviation). At the univariate level, Chi-square tests were performed to determine the association between dependent and independent variables. Bivariate analyses were used to compute the unadjusted associations between the use of HIV prevention strategies and independent variables, including socio-demographic characteristics (such as age, marital status, level of education, sex and occupation of participants), and HIV prevention strategies offered by religious leaders (such as; condom use, being faithful, abstinence, raising awareness, advocating for voluntary medical male circumcision). The results were expressed in terms of odds ratio at a $95 \%$ level of confidence and a $P$ value $<0.05$. Variables that were significant in the bivariate analysis $(p<0.05)$ were considered for the multivariable analysis. We conducted multivariable analysis using the independent variables that are statistically significant during the bivariate analysis and those considered plausible although not significant against 
the dependent variable. Logistic regression was performed to come up with a suitable model to explain the predictors of use of HIV prevention strategies among young people and the statistical significance of $\mathrm{p}<0.05$. Qualitative data was analyzed using thematic content analysis according to Bruno Clarke, (2006) that describes seven steps of data analysis including1) transcription, 2) reading and familiarization 3) coding, 4) searching for themes, 5) review of themes, 6)naming the themes, 7) finalizing the analysis and interpretation of the results.

\section{Results}

\section{The prevalence of use of HIV prevention among young people.}

The prevalence of the participants who use HIV prevention strategies was 69.4\% (293/422).

\section{Social demographic characteristics of the respondents}

A total of 422 participants were interviewed using an interviewer administered questionnaire with a $100 \%$ response rate. The mean age of the respondents was $19.18(S D= \pm 2.6)$ with $56.9 \%(240 / 422)$ in the age category of less than 20 years. About $71.8 \%$ (303/422) of the respondents were singles and $57.1 \%$ (241/422) were females. The majority of respondents, $45 \%$ (190/422), had completed an ordinary level of education. (Table 1)

\section{HIV prevention strategies provided by religious leaders}

The majority of participants, $85 \%$ (362/422), reported that their religious leaders advocate for abstinence. In addition, the majority, $95 \%$ (401/422) of the participants, reported that their religious leaders advocated for faithfulness (Table 2). Participants in the qualitative interviews strongly supported or advocated for abstinence, particularly among unmarried young people, and for being faithful to one partner among married people. One respondent reported that:

"Abstinence is the best. We discourage premarital sex for two reasons: one, you don't go when there isn't time, and there is time for everything. Sex is good, but in a marriage setting, it's inappropriate. "So, according to Galatians 5:19, we reject and condemn fornication among young people, and we discourage and condemn adultery. "The only good way is abstinence and patience. "Male, SDA, R16, 38 years, March 2021.

As far as condom use is concerned, religious leaders have varying opinions concerning their support for condom use. Therefore, the message regarding condom use as one of the HIV prevention strategies by religious leaders cannot be ignored. A significant proportion, 71.8\% (303/422) of the respondents, reported that their religious leaders discouraged condom use (Table 2). This result was further supported by a section of religious leaders who reported discouraging condom use among young people. Those 
who don't support condom use argue that it promotes fornication and adultery among the youth. Some of the key informants remarked:

"Using condoms is not good for them because it allows them to engage in sexual relationships, which can easily lead to the spread of HIV/AIDS among young people" When you read Exodus 20 in the Bible, it talks about avoiding fornication, and the church teaches the youth not to engage in sexual relationships". Male, SDA, R12, 50 years, March 2021.

According to another key informant:

"... Because of respecting the law, just like I swore, it makes me accept what the church has accepted. But what the church has refused, I will also refuse"Male, Catholic, R5, 30 years, March 2021.

A level of ambivalence was articulated by one of the key informants who was able to detach himself from his religion and reported he would encourage young people to use condoms because it would prevent them from contracting the virus, as quoted below:

".... "Leaving aside the issue of being a catechist, it is to advise a child to go to the hospital and get a condom in order to prevent a child from contracting the virus"Male, Catholic, R6, 42 years, March 2021.

About 51.2\% (216/422) reported that their religious leaders have never advocated for voluntary medical male circumcision (Table 2). According to some qualitative interview participants, male circumcision is not a safer method of HIV prevention among young people, as one can still contract the disease and it encourages sexual relationships. One religious leader said:

"It makes one have uncontrollable sexual behavior." Male, Anglican, R11, 46 years, March 2021.

A significant proportion of participants, $65.2 \%$ (275/422), reported that their religious leaders preach about HIV prevention. The same message was echoed by participants in the key informant's interviews. One participant reported:

"We preach to them and we encourage them to carry out tests to know their status as well. For those that already know their status, we always give them words of hope that that's not the end of life" Male, Anglican, R19, 39 years.

About $61.9 \%(261 / 422)$ of the respondents reported that their religious leaders are involved in awareness creation programs among young people (Table 2). A section of the religious leaders reported not having posters/charts with HIV prevention messages in their various places of worship. If they are available, some people prefer to hang them in their places of worship. One participant was quoted as saying;

"...So my opinion is that it should not be hung against the wall in the church because it's the house of the Lord, but it can be hung outside the church in the compound."Female, Pentecostal, R4, 50 years, March 2021. 
The majority, 47.4\% (200/422) of young people, reported that religious leaders have a strong influence on their use of HIV prevention strategies. A significant number, 47.9\% (202/422) reported that religious leaders' preaching influences their choice of HIV prevention strategy. Moreover, most $61.9 \%(261 / 422)$ of the participants reported that their religious leaders are involved in HIV/AIDS awareness campaigns (Table 2). This result is consistent with the results of the key informant's interviews. One participant reported:

They have training most of the time during camp meetings, in the 13th week, and the church also organizes youth meetings once a month. We also have an Adventist Youth group that we teach about the dangers and prevention of HIV/AIDS, and we have books like 'Free from Addiction' that we give people to read about HIV/AIDS." All of these programs are aimed at youths as well. "Male, SDA, R12, 50 years.

About $47.4 \%$ (200/422) of the respondents reported that religious leaders have a strong influence on their choice of HIV prevention strategies.

\section{Bivariate and multivariable logistic regression of factors associated with use of HIV prevention strategies among young people.}

Factors significantly associated with the use of HIV prevention include completion of the primary level (aOR 4.95, p < 0.05), completion of at least A level (aOR 8.85, $p<0.05$ ), awareness of HIV prevention strategies by religious leaders (aOR $0.02, p<0.001$ ), provision of HIV prevention messages from religious leaders (aOR 2.53, $p<0.01$ ), Advocacy for being faithful (aOR 35.6, $p<0.01$ ), Religious leaders preaching about HIV prevention (aOR 4.88, $\mathrm{p}<0.001$ ). (Table 3 )

\section{Discussion}

In our study in which we assessed the utilization of HIV prevention strategies provided by religious leaders among young people, we found nearly $70 \%$ of the participants reported using these HIV prevention strategies. In these settings, religious leaders are held in high esteem and they are viewed as trustworthy sources of information and guidance and compliance with their teaching could help prevent HIV among young people. This finding is consistent with other evidence where it is believed that religious leaders teach values whose obedience is likely to protect communities against HIV/AIDS [21]. In addition, evidence from elsewhere shows that religious leaders can help in the dissemination of health information, more specifically HIV prevention, to the communities that they serve [20, 22]. In other settings, however, some religious leaders have been reprimanded by their religious authorities and censored for preaching to their congregants on the subject of HIV/AIDS. These actions are often driven by the negative association between HIV/AIDS and immorality, particularly in the form of promiscuity, and could impede progress in the fight against HIV. Furthermore, religious leaders have been accused of spreading false information; for example, making claims that prayers can heal HIV $[22,23]$ and unhealthy attitudes and behaviors create a barrier to prevention success among young people [24]. Among some religious leaders, HIV/AIDS is considered God's punishment for sins such as being sexually promiscuous 
[25]. This implies that some religious leaders simply do not have the requisite knowledge of HIV/AIDS and its prevention.

The religious leaders' creation of awareness was one of the reasons for the high utilization of HIV prevention strategies among young people. Our results also show that about $61.9 \%$ of young people reported that their religious leaders are involved in HIV/AIDS awareness campaigns. Our results also show that about $61.9 \%$ of the young people reported that their religious leaders are involved in HIV/AIDS awareness campaigns. This could be attributed to the fact that some religions are actively involved in HIV prevention, care and management [26]. Furthermore, some religious leaders stated that they organize workshops and seminars to teach young people about HIV prevention. This finding is in line with evidence from Senegal, where religious leaders were more likely to report teaching prevention [20]. Awareness created through religious engagements is likely to impact positively on the fight against HIV/AIDS among young people. In addition, those who were aware of HIV prevention strategies were more likely to use HIV prevention strategies as opposed to those who were not. These findings are consistent with data from other settings [27].

Our results also indicate that young people who were preached to about HIV prevention were more likely to use HIV prevention strategies provided by religious leaders. Preaching would lead to awareness creation, which empowers young people to be able to make better decisions as far as HIV prevention is concerned. Religious leaders are considered as moral authorities in their settings, and can be given platforms during religious gatherings, funerals, marriages and ceremonies, to preach about appropriate sexual behavior and other significant information regarding HIV prevention [28, 29]. Moreover, this finding is consistent with evidence from Malawi, where preaching about AIDS is a common activity for HIV prevention $[16,26,30]$.

In our study, abstinence outside marriage and being faithful among the married were the most advocated strategies by religious leaders. Younger people whose religious leaders preached about abstinence and fidelity were 35.6 times more likely to use HIV prevention strategies compared to those who were not. Preaching is likely to result in more religiously enhanced behaviors that are beneficial to HIV prevention and lead to a constructive reduction in HIV spread and lower HIV prevalence [25,31-33]. This is because abstinence and fidelity are rooted in most religious beliefs, and such values have the potential to lower the risk of HIV acquisition. The Holy Bible, for example, forbids adultery and fornication (Galatians 5:19). Our findings are consistent with what other scholars have observed elsewhere where sexual abstinence and mutual fidelity are encouraged as opposed to condom use that is viewed as undermining morality $[22,27]$. This suggests that religious leaders place a greater emphasis on behavioral mechanisms, which are an important part of enforcing social values.

Our findings indicate that only $28 \%$ of young people reported their religious leaders advocating for condom use. Additionally, a huge proportion of religious leaders are not in favor of condoms being used as a prevention strategy. Condom use is viewed as a promotion of sexual immorality in many religious faiths, and in most cases, faith-based organizations have been reported to demonize condom use as 
promoting sinful behavior [28]. Catholicism, for example, forbids the use of condoms, even as a method of family planning. This finding is also consistent with evidence observed by other scholars in other settings [19, 20,30,34]. Nevertheless, some of the religious leaders in this study were able to detach themselves from their religions. For example, a section of religious leaders reported that they would advise young people to use condoms even though it is against the beliefs of their religion. As one respondent said, "many ways of HIV AIDS prevention are there, like condom use, but the church does not encourage this.

Religious leaders have shown a willingness to learn about and participate in HIV prevention in some settings, proving to be a valuable partner in the fight against the pandemic [16, 24, 27, 30,35]. Over the years, efforts have been made to involve religious leaders in addressing issues related to HIV/AIDs. For example, an inter-religious project that provides training for religious leaders with scientific information supported by both Muslim and Christian faith teachings was piloted in 1995 and has evolved to address several HIV-related community needs [25]. However, according to some religious leaders in our qualitative results, their role was limited by a lack of training, inadequate equipment and facilitation to carry out HIV prevention programs. Similar results were obtained from a study in Nigeria [36].

However, our study had some limitations. Our data did not include the Traditional African Religious (TAR) leaders. The focus of our study was on modern religious leaders because it was challenging to detach the TAR leaders from their traditional beliefs from their spiritual components. In addition, we were unable to assess the age of initiation into sex, which would have been a good indicator of the level of risk. We did not assess the effect of other prevention strategies, for example, the media, and peer education. These are potential areas of future research in a similar setting. This study, on the other hand, was able to separate religious leaders from their religious affiliations, at least in some cases. And it highlights the importance of religious leaders and their readiness to participate in HIV prevention among young people

\section{Conclusion And Recommendations}

We have found that religious leaders can play a pivotal role in HIV prevention among young people. The predictors of use of HIV prevention strategies provided by religious leaders include completion of an advanced level of education, awareness of HIV prevention strategies by religious leaders, provision of HIV prevention messages from religious leaders, advocacy for being faithful and religious leaders preaching about HIV prevention. Our study resonates with previous findings and builds on existing literature to highlight the role of religious leaders in the use of HIV prevention strategies among young people in resource-constrained settings. The benefit of the role of religious leaders is that they are considered as moral authorities in their settings, and are given platforms during religious gatherings, funerals, marriages and ceremonies, to educate them about appropriate sexual behavior and other significant information regarding HIV prevention. Efforts to train and harmonize key messages on HIV prevention messages, improved access to information, education, and communication (IEC) materials, and improvement in the level of education of young people will promote the use of HIV prevention strategies among young people. 


\section{Declarations}

\section{Ethics approval and consent to participate}

The authors confirm that appropriate institutional approvals were obtained, and that all methods in this study were carried out in accordance with the relevant guidelines and regulations. The study protocol was reviewed and cleared by the Gulu University Research Ethics Committee (GUREC-2021-34). Permission to conduct the study was sought from the Resident City Commissioner of Lira City and the Resident District Commissioner of Lira district. Permission to conduct the study was further obtained from the heads of different churches and mosques before data collection. Written informed consent was sought from all respondents before interviews were conducted. The informed consent process included providing explanations about the purpose and objectives of the study, the procedures, benefits and risks to be borne by the respondent and reassurance of confidentiality. To ensure confidentiality, all information regarding respondents remained confidential within the study team. Unique numerical identifiers were used for computer-based data entry and to conceal the identity of the participants. All respondents were free to participate without any form of coercion. Informed consent was sought from all participants above 18 years and those under 18 years assent was sought as well as consent from a parent and/or legal guardian.

\section{Consent for publication}

Not applicable

\section{Availability of data and materials}

The datasets used in this study are available upon reasonable request from the corresponding author.

\section{Competing interests}

The authors declare that they have no competing interests.

\section{Funding source}

Research reported in this publication was supported by the Fogarty International Center (U.S. Department of State's Office of the U.S. Global AIDS Coordinator and Health Diplomacy [S/GAC] and the President's Emergency Plan for AIDS Relief [PEPFAR]) of the National Institutes of Health under Award Number R25TW011210. The content is solely the responsibility of the authors and does not necessarily represent the official views of the National Institutes of Health.

\section{Authors' Contributions}

TM, IK, PO, MM, PG, MJA, SSP conceptualized the study. TM, IK, PO, MM, PG, MJA, LA and SSP participated in the development of the protocol. TM, LA and SSP participated in data analysis and LA and SSP substantively revised the manuscript. All the authors read and approved the manuscript for 
publication and have agreed both to be personally accountable for the author's own contributions and to ensure that questions related to the accuracy or integrity of any part of the work, even ones in which the author was not personally involved, are appropriately investigated, resolved, and the resolution documented in the literature.

\section{Acknowledgements}

We thank the study participants for taking the time to participate in this research. We also acknowledge the efforts of Prof. Obua Celestino, Dr. Wakida Edith and Ms. Gutu Justine for the support they provided during this research project. We thank Dr. Ocan Moses and Mr. Opio Bosco for their technical input during the analysis and drafting of the manuscript. Last, we thank Ms. Uwera Francine for proof reading our work.

\section{References}

1. UNAIDS, Global HIV \& AIDS statistics - Fact sheet. 2020.

2. UNAIDS, Joint United Nations Programme on HIV/AIDS. Report on the Global Acquired Immunodeficiency Syndrome Epidemic. UNAIDS.. 2008.

3. UNAIDS, < 2020_aids-data-book_en.pdf>. 2020.

4. UNICEF, WHAT RELIGIOUS LEADERS CAN DO ABOUT HIVAIDS Action for Children andYoung People. 2019.

5. Kharsany, A.B. and Q.A. Karim, HIV Infection and AIDS in Sub-Saharan Africa: Current Status, Challenges and Opportunities. Open AIDS J, 2016. 10: p. 34-48.

6. (UBOS), U.B.o.S., National Population and Housing Census, 2014. Kampala: UBOS; 2016.. 2016.

7. Schuyler, A.C., et al., Mobility among youth in Rakai, Uganda: Trends, characteristics, and associations with behavioural risk factors for HIV. Global public health, 2017. 12(8): p. 1033-1050.

8. Geier, C.F., Adolescent cognitive control and reward processing: implications for risk taking and substance use. Hormones and behavior, 2013. 64(2): p. 333-342.

9. Kassahun, E.A., et al., Factors associated with early sexual initiation among preparatory and high school youths in Woldia town, northeast Ethiopia: a cross-sectional study. BMC public health, 2019. 19(1): p. 378.

10. Baisley, K., et al., High HIV incidence and low uptake of HIV prevention services: The context of risk for young male adults prior to DREAMS in rural KwaZulu-Natal, South Africa. PLoS One, 2018. 13(12): p. e0208689.

11. Michielsen, K., Limited effectiveness of HIV prevention for young people in sub-Saharan Africa: studying the role of intervention and evaluation. Facts, views \& vision in ObGyn, 2013. 5(3): p. 196.

12. Ssebunya, R.N., et al., Prevalence and correlates of HIV testing among adolescents 10-19 years in a post-conflict pastoralist community of Karamoja region, Uganda. BMC public health, 2018. 18(1): p. 1-8. 
13. State, U.S.D.o., <UGANDA-2019-INTERNATIONAL-RELIGIOUS-FREEDOM-REPORT.pdf>. 2019.

14. Lightfoot, M., et al., <Religious-groups-as-diffusers-of-HIV-antibody-testing-and-preventionmessages.pdf>. JOURNAL OF COMMUNITY PSYCHOLOGY,, 2001. Vol. 29, (No. 4,): p. 459-472

15. UNFPA, <annual_report03_eng.pdf>. 2003.

16. Gichuru, E., et al., Engaging religious leaders to support HIV prevention and care for gays, bisexual men, and other men who have sex with men in coastal Kenya. Crit Public Health, 2018. 28(3): p. 294-305.

17. Endeshaw, M., et al., Involving religious leaders in HIV care and treatment at a university-affiliated hospital in Ethiopia: Application of formative inquiry. Global public health, 2017. 12(4): p. 416-431.

18. UNAIDS, World AIDS Day Report. 2012.

19. Rakotoniana, J.S., M.R. Jean de Dieu, and H. Barennes, Can churches play a role in combating the HIV/AIDS epidemic? A study of the attitudes of Christian religious leaders in Madagascar. PloS one, 2014. 9(5): p. e97131.

20. Ansari, D.A. and A. Gaestel, Senegalese religious leaders' perceptions of HIV/AIDS and implications for challenging stigma and discrimination. Cult Health Sex, 2010. 12(6): p. 633-48.

21. Francis, S.A. and J. Liverpool, A review of faith-based HIV prevention programs. J Relig Health, 2009. 48(1): p. 6-15.

22. Asekun-Olarinmoye, I.O., et al., Perceptions and activities of religious leaders on the prevention of HIVIAIDS and care of people living with the HIV infection in Ibadan, Nigeria. HIV AIDS (Auckl), 2013. 5: p. 121-9.

23. Wanyama, J., et al., Belief in divine healing can be a barrier to antiretroviral therapy adherence in Uganda. AIDS, 2007. 21(11): p. 1486-7.

24. Genrich, G.L. and B.A. Brathwaite, Response of religious groups to HIV/AIDS as a sexually transmitted infection in Trinidad. BMC Public Health, 2005. 5: p. 121.

25. Kagimu, M., et al., Inter-religious Cooperation for HIV Prevention in Uganda: A Study among Muslim and Christian Youth in Wakiso District. Religions, 2011. 2(4): p. 707-728.

26. Surur, F. and M. Kaba, The role of religious leaders in HIV/AIDS prevention, control, and patient care and support: A pilot project in Jimma Zone.. Northeast African Studies, 2000. 7(2): p. 59-79.

27. Abu-Moghli, F., et al., Islamic religious leaders' knowledge and attitudes towards AIDS and their perception of people living with HIV/AIDS: a qualitative study. Scand J Caring Sci, 2010. 24(4): p. 655-62.

28. Rankin, S.H., et al., The condom divide: disenfranchisement of Malawi women by church and state. J Obstet Gynecol Neonatal Nurs, 2008. 37(5): p. 596-604; quiz 604-6.

29. Kanda, K., et al., Religious leaders as potential advocates for HIV/AIDS prevention among the general population in Sri Lanka. Glob Public Health, 2013. 8(2): p. 159-73.

30. Trinitapoli, J., The AIDS-related activities of religious leaders in Malawi. Glob Public Health, 2011. 6(1): p. 41-55. 
31. Mbulaiteye, S.M., et al., Alcohol and HIV: a study among sexually active adults in rural southwest Uganda. Int J Epidemiol, 2000. 29(5): p. 911-5.

32. Rakwar, J., et al., Cofactors for the acquisition of HIV-1 among heterosexual men: prospective cohort study of trucking company workers in Kenya. AIDS, 1999. 13(5): p. 607-14.

33. Gray, P.B., HIV and Islam: is HIV prevalence lower among Muslims? Soc Sci Med, 2004. 58(9): p. 1751-6.

34. Trinitapoli, J. and M.D. Regnerus, Religion and HIV Risk Behaviors Among Married Men: Initial Results from a Study in Rural Sub-Saharan Africa. Journal for the scientific study of religion, 2006. 45(4): p. 505-528.

35. Hare, M.L. and A.M. Villarruel, Cultural dynamics in HIV/AIDS prevention research among young people. J Assoc Nurses AIDS Care, 2007. 18(2): p. 1-4.

36. Oluduro, O., The role of religious leaders in curbing the spread of HIV/AIDS in Nigeria. Potchefstroom Electronic Law Journal/Potchefstroomse Elektroniese Regsblad, 2010. 13(3).

\section{Tables}


Table 1: Shows the young peoples' socio-demographic characteristics Variables Frequency $(n=422) \quad$ Percentage $(\%) \quad P$-value

Sex of respondents

$\begin{array}{llll}\text { Female } & 241 & 57.1 & 0.721 \\ \text { Male } & 181 & 42.9 & \end{array}$

Age of respondents

$\begin{array}{llll}₫ 20 & 240 & 56.9 & \\ \geq 20 & 182 & 43.1 & 0.023\end{array}$

Place of residence of respondents

$\begin{array}{llll}\text { Rural } & 202 & 47.9 & \\ \text { Urban } & 220 & 52.1 & 0.874\end{array}$

Religion of respondents

\begin{tabular}{|llll|}
\hline Catholic & 138 & 32.7 & 0.896 \\
\hline Protestant & 112 & 26.5 & \\
\hline Pentecostal & 60 & 14.2 & \\
\hline Seventh day Adventist & 85 & 20.1 & \\
\hline Orthodox & 11 & 2.6 & \\
\hline Muslim & 16 & 3.8 & \\
\hline Marital status of respondents & & & \\
\hline Single & 303 & 71.8 & 0.215 \\
\hline Cohabiting & 22 & 5.2 & \\
\hline Never married & 50 & 11.9 & \\
\hline Separated & 13 & 3.1 & \\
\hline Married & 34 & 8.1 & \\
\hline Highest education level of respondents & & & \\
\hline No formal education & 20 & 4.8 & $<0.001$ \\
\hline Completed Primary education & 144 & 34.1 & \\
\hline Completed O'level education & 190 & 45.0 & \\
\hline Advanced level plus & 68 & 16.1 & \\
\hline
\end{tabular}




\begin{tabular}{|c|c|c|c|}
\hline \multicolumn{4}{|c|}{ Occupation of respondents } \\
\hline Non formal & 62 & 14.7 & 0.516 \\
\hline Student & 291 & 69.0 & \\
\hline Business & 49 & 11.6 & \\
\hline Formal employment & 20 & 4.7 & \\
\hline
\end{tabular}

Table 2: Perceptions and HIV prevention strategies provided by religious leaders 


\section{Variables}

Frequency $(n=422)$

Percentage (\%)

P-value

Do your religious leaders advocate for abstinence outside marriage?

$\begin{array}{llll}\text { No } & 60 & 14.2 & \\ \text { Yes } & 362 & 85.8 & <0.001\end{array}$

Do your religious leaders advocate for fidelity in marriage?

$\begin{array}{llll}\text { No } & 21 & 5.0 & \\ \text { Yes } & 401 & 95.0 & <0.001\end{array}$

Do your religious leaders advocate for Condom use?

$\begin{array}{llll}\text { No } & 303 & 71.8 & \\ \text { Yes } & 119 & 28.2 & 0.577\end{array}$

Do your religious leaders advocate for voluntary medical male circumcision?

$\begin{array}{llll}\text { No } & 216 & 51.2 & \\ \text { Yes } & 206 & 48.8 & <0.003\end{array}$

Do your religious leaders advocate for HCT?

$\begin{array}{llll}\text { No } & 42 & 10.0 & \\ \text { Yes } & 380 & 90.0 & <0.001\end{array}$

Do your religious leaders preach about HIV prevention?

$\begin{array}{llll}\text { No } & 147 & 34.8 & \\ \text { Yes } & 275 & 65.2 & <0.001\end{array}$

Are there specific HIV prevention strategies provided at your church/mosque?

$\begin{array}{llll}\text { No } & 220 & 52.1 & \\ \text { Yes } & 202 & 47.9 & <0.001\end{array}$

Reported religious leaders involved in HIV awareness campaign among young people

$\begin{array}{llll}\text { No } & 161 & 38.1 & \\ \text { Yes } & 261 & 61.9 & <0.001\end{array}$

Do you get routine HIV counseling at your church/mosque?

$\begin{array}{lrrr}\text { No } & 222 & 52.6 & \\ \text { Yes } & 200 & 47.4 & <0.001\end{array}$

The religious leaders have a strong influence on the choice of HIV prevention strategies 


\begin{tabular}{|c|c|c|c|}
\hline Strongly disagree & 34 & 8.1 & \multirow[t]{4}{*}{$<0.001$} \\
\hline Disagree & 72 & 17.1 & \\
\hline Agree & 200 & 47.4 & \\
\hline Strongly agree & 116 & 27.4 & \\
\hline \multicolumn{4}{|c|}{ The preaching of your religious leaders affects choice of HIV prevention strategy } \\
\hline Strongly disagree & 47 & 11.1 & \multirow[t]{4}{*}{$<0.001$} \\
\hline Disagree & 78 & 18.5 & \\
\hline Agree & 202 & 47.9 & \\
\hline Strongly agree & 95 & 22.5 & \\
\hline \multicolumn{4}{|c|}{ The involvement of religious leaders in HIV/AIDS prevention helps prevent HIV among young peop } \\
\hline Strongly disagree & 39 & 9.2 & \multirow[t]{4}{*}{$<0.001$} \\
\hline Disagree & 78 & 18.5 & \\
\hline Agree & 188 & 44.6 & \\
\hline Strongly agree & 117 & 27.7 & \\
\hline
\end{tabular}

Table 3 Bivariate and multivariable logistic regression of factors associated with use of HIV prevention strategies among young people 


\begin{tabular}{|c|c|c|c|c|}
\hline \multirow[t]{2}{*}{ Variables } & \multicolumn{4}{|c|}{ Use of HIV prevention strategies } \\
\hline & Yes & No & Crude OR $(95 \% \mathrm{Cl})$ & $\begin{array}{l}\text { Adjusted OR } \\
95 \% \mathrm{Cl}\end{array}$ \\
\hline \multicolumn{5}{|l|}{ Highest level of education completed } \\
\hline Education level Primary & 91 & 53 & $\begin{array}{l}1.72(0.671- \\
4.394)^{N S}\end{array}$ & $\begin{array}{l}4.95(1.421- \\
17.220)^{\star}\end{array}$ \\
\hline Completed O' Level & 129 & 61 & $\begin{array}{l}2.11(0.836- \\
5.349)^{N S}\end{array}$ & $\begin{array}{l}2.24(0.721- \\
6.973)\end{array}$ \\
\hline Completed at least $A^{\prime}$ level & 63 & 5 & $\begin{array}{l}12.60(3.560- \\
44.596)^{\star \star \star}\end{array}$ & $\begin{array}{l}8.85(2.018- \\
38.794)^{*}\end{array}$ \\
\hline $\begin{array}{l}\text { Aware of HIV prevention strategies by } \\
\text { religious leaders }\end{array}$ & 6 & 82 & $\begin{array}{l}0.01(0.005- \\
0.029)^{\star \star \star}\end{array}$ & $\begin{array}{l}0.02(0.006- \\
0.052) \star \star \star\end{array}$ \\
\hline $\begin{array}{l}\text { Received HIV prevention strategies from } \\
\text { Religious leaders }\end{array}$ & 269 & 24 & $\begin{array}{l}3.72(1.844- \\
7.525) \star \star \star\end{array}$ & $\begin{array}{l}2.53(1.045 \\
6.110)^{* \star}\end{array}$ \\
\hline $\begin{array}{l}\text { Do religious leaders advocate for being } \\
\text { faithful }\end{array}$ & 292 & 109 & $\begin{array}{l}2.17(1.315- \\
3.575)^{\star \star}\end{array}$ & $\begin{array}{l}35.6(3.639- \\
348.998)^{\star \star}\end{array}$ \\
\hline $\begin{array}{l}\text { Do your religious leaders preach about HIV } \\
\text { prevention }\end{array}$ & 235 & 40 & $\begin{array}{l}5.13(2.052- \\
12.813)^{\star \star \star}\end{array}$ & $\begin{array}{l}4.88(2.504- \\
9.517)^{\star \star \star}\end{array}$ \\
\hline
\end{tabular}

Level of significance ${ }^{*} p<0.05,{ }^{* *} p<0.01,{ }^{* *} p<0.001$ NS Not significant 